\title{
Changes in properties of tar obtained during underground coal gasification process
}

\author{
Marian Wiatowski $^{1}$ (D) Roksana Muzyka $^{2} \cdot$ Krzysztof Kapusta $^{1} \cdot$ Maciej Chrubasik $^{2}$
}

Received: 15 December 2020/Revised: 18 February 2021/Accepted: 29 April 2021/Published online: 10 June 2021

(C) The Author(s) 2021

\begin{abstract}
In this study, the composition of tars collected during a six-day underground coal gasification (UCG) test at the experimental mine 'Barbara' in Poland in 2013 was examined. During the test, tar samples were taken every day from the liquid product separator and analysed by the methods used for testing properties of typical coke oven (coal) tar. The obtained results were compared with each other and with the data for coal tar. As gasification progressed, a decreasing trend in the water content and an increasing trend in the ash content were observed. The tars tested were characterized by large changes in the residue after coking and content of parts insoluble in toluene and by smaller fluctuations in the content of parts insoluble in quinoline. All tested samples were characterized by very high distillation losses, while for samples starting from the third day of gasification, a clear decrease in losses was visible. A chromatographic analysis showed that there were no major differences in composition between the tested tars and that none of the tar had a dominant component such as naphthalene in coal tar. The content of polycyclic aromatic hydrocarbons (PAHs) in UCG tars is several times lower than that in coal tar. No light monoaromatic hydrocarbons (benzene, toluene, ethylbenzene and xylenes-BTEX) were found in the analysed tars, which results from the fact that these compounds, due to their high volatility, did not separate from the process gas in the liquid product separator.
\end{abstract}

Keywords Underground coal gasification · UCG $\cdot$ Pilot trial · Tar $\cdot$ BTEX $\cdot$ PAHs $\cdot$ Phenols

\section{Introduction}

The process of underground coal gasification (UCG) is considered to be one of the forms of clean coal technologies for obtaining gaseous fuel and synthesis gas from hard coal (Burton et al. 2006; Bhutto et al. 2013; Cough 2009). In the situation of increasingly smaller coal resources available for economically justified mining and the unfavorable impact of coal combustion on the environment, with a simultaneous prospect of continuous growth of

Marian Wiatowski

mwiatowski@gig.eu

1 Central Mining Institute, Plac Gwarków 1, 40-166 Katowice, Poland

2 Institute for Chemical Processing of Coal, 1 Zamkowa St, 41-803 Zabrze, Poland energy demand, it seems advisable to undertake research on this technology.

The idea of underground gasification of coal directly in the coal seam was developed at the beginning of the twentieth century in England (Review of the feasibility 2004; Gregg and Edgar 1978) and in the former Soviet Union (Klimenko 2009; Kreinin et al. 1982), and these works were continued after World War II. Currently, after many years of research and trials on an industrial scale conducted around the world (mainly in the USA, China, Australia, South Africa, Russia, Canada and Poland), the technology of underground coal gasification is still not fully mature for its widespread use on an industrial scale (Greg 2018). The only active installation in which underground coal gasification is carried out on an industrial scale is located in Angren (Uzbekistan), located on the territory of the former Soviet Union (Olness 1982). This installation 
has been operating since 1961, supplying low-calorific gas to a nearby power plant. At present, this installation is operating at a low efficiency of approximately $20 \%$, more as a demonstration facility for potential foreign investors. Therefore, further research is needed to make these technologies applicable on a mass scale.

The coal gasification process is a combination of several simultaneous reactions: pyrolysis, combustion and gasification with complex kinetics, which are difficult to define unequivocally (Cena and Thorness 1981). In this process, apart from gas, which is its main product, liquid products are also obtained in the form of tar with water and solids, which are the remainder of the process. The content of tar products in the obtained gas depends on the process conditions and ranges from 0.5 to $15.5 \mathrm{~g} / \mathrm{m}^{3}$ (Pavlovich and Strakhov 2013; Chiranjeeva et al. 2015; Wiatowski et al. 2017). Condensing liquid products constitute an impurity of the produced gas and should be removed when using gas as a chemical raw material practically completely. The most important factors affecting the amount and composition of tars in the process gas are the temperature conditions in the reactor and in the pipeline transporting hot gases to the surface. The tar starts to evolve from coal at temperatures of $350-400{ }^{\circ} \mathrm{C}$ (Elliott 1981; Karabon 2002; Vreugdenhil and Zwart 2009) and ends at approximately $1000{ }^{\circ} \mathrm{C}$. During this time, tar undergoes many processes (Barbour and Cummings 1986; Barbour et al. 1988), as a result of which its quantity and composition change.

With a short residence time and lower temperatures in the underground reactor (which depend mainly on the size of the gasified seam, intensity and flow conditions of the gasifying agent and its concentration), the tar will be less affected by secondary processes (Akbarzadeh and Chalaturnyk 2014), e.g. thermal cracking. As a result, such tar will contain heavier compounds with two or more ring structures and fewer BTEX compounds compared to the one that has been in the reactor for a longer time. After leaving the reactor, tar is transported in a process gas stream to the surface. Depending on the temperature in the outlet pipeline, tar may continue to undergo the process of secondary cracking. The higher the intensity, the higher the temperatures and the longer the residence tar in the pipeline. Moreover, due to the temperature difference between the beginning and end of the pipeline, the heavier components of tar are liquefied (fractional distillation), and only the lighter components reach the surface (Liu et al. 2020; Philips and Muela 1977). Condensation of tar in the pipeline is very unfavourable because the pipeline diameter decreases; in extreme cases, it may become clogged (Department of Energy 2009). On the other hand, a high content of tar products in the gas negatively affects the properties of the produced gas and makes it necessary to build an effective system of gas purification and tar separation. Additionally, high tar content causes problems with its management (it is a dangerous and troublesome waste), and there may also be a possibility of groundwater contamination in the case of migration of tar components into the rock mass (Liu et al. 2007).

All factors that occur in tar from its formation to the transport in the process gas to the surface are the cause of the variable yield of tar products in the gas and the fluctuation of their properties in a way that is difficult to predict. Since the main purpose of UCG is to obtain as much process gas as possible with a high calorific value, the gasification conditions must be optimized so that the amount of tar obtained is as low as possible.

Information on the quantity and properties of tars obtained in the UCG process is the basis for the decision to dispose of tar products separated from the process gas. One of the potential ways of using tars from the coal gasification process is to connect it to the stream of mass-produced coal tar produced in coking plants and processed by distillation. However, such management of coal gasification tars requires their appropriate adaptation to a quality that does not differ from the parameters of coal tar. This is necessary from the point of view of the quality requirements for the products of tar processing, especially coal tar pitch, to avoid deterioration of commercial products. This is mainly due to the excessive content of ash and inert parts, which are determined as substances insoluble in toluene and quinoline. As an alternative, other uses of tars with UCG can also be considered, including the most unfavourable option of disposal as hazardous waste. To test this possibility, it is necessary to know the properties of tars produced during the real process of underground coal gasification. There is little information in the available literature about this topic. Therefore, the aim of this study was to determine the range of variability of the basic properties of tars from the process of underground coal gasification, which will be the basis for indicating potential methods of their utilization. The obtained results were compared with the properties of typical coal tar, which made it possible to adopt a certain reference level for the tested tars from the UCG process.

\section{Experimentals}

\subsection{Design and construction of UCG installation}

The installation for coal gasification was built and located at the experimental mine 'Barbara' in Mikołów, Poland. It consisted of a surface and underground parts. As shown in Fig. 1, the installation for UCG consisted of the following systems: oxidizer supply, underground reactor, gas cooling, collection and dewatering. An important part of the 


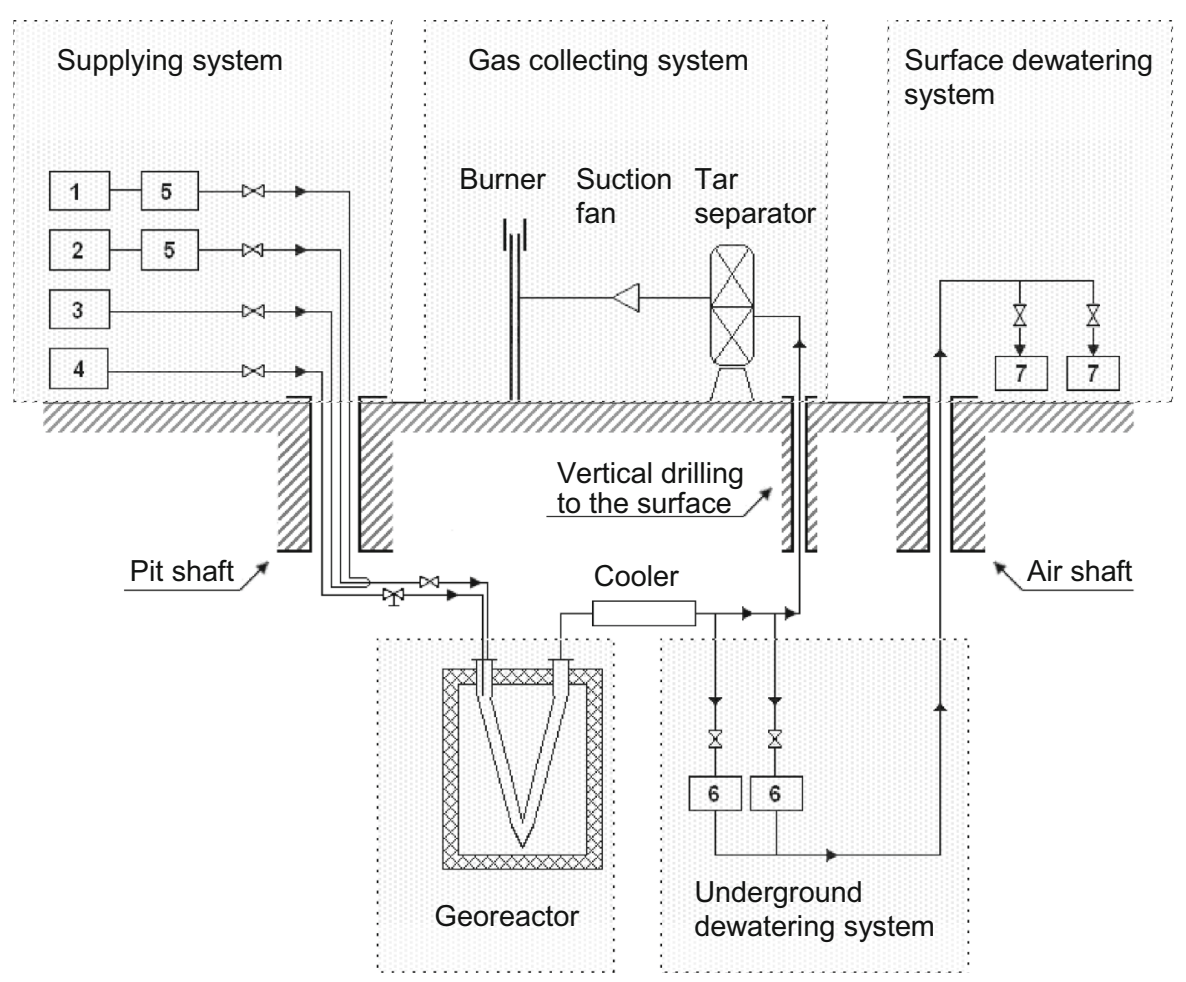

Fig. 1 Arrangement of installation elements: 1-liquid oxygen tank, 2-liquid nitrogen tank, 3-air compressor, 4-water supply, 5-gas evaporators, 6-dewaterers, 7-tanks (Wiatowski et al. 2015)

installation was the control and measurement apparatus with operation and safety monitoring assurance. The gasifying agent was oxygen, and for safety reasons, access to nitrogen was also provided. Coal gasification was carried out in an underground reactor located in seam no. 310 at a depth of $30 \mathrm{~m}$ and seam thickness of $1.5 \mathrm{~m}$. The horizontal V-shaped fire channel had two 0.14-m-diameter and 17.3m-long holes.

After leaving the reactor, the hot process gases passed through an underground water cooler and were then directed to a gaseous product collection system located on the surface. After tar separation, the process gas was directed to the thermal combustor, where it was burned. The scheme of the gaseous product collection system is shown in Fig. 2.

\subsection{Measurements of the process temperatures and gas composition}

The temperature of the process gases at the reactor outlet was measured with a $\mathrm{K}$ type thermocouple (measurement error $\pm 1.0^{\circ} \mathrm{C}$ ), and behind the water cooler and at the tar sampling point with a Pt100 resistance sensor (measurement error $\pm 0.3{ }^{\circ} \mathrm{C}$ ). The process gas was sampled directly from the pipeline, downstream the suction fan (Fig. 2). The gas composition was analysed every $30 \mathrm{~min}$. using a gas chromatograph Agilent 3000A.

\subsection{Analysis of gasified coal}

An analysis of gasified coal is presented in Table 1 . The coal analysis was performed in a certified laboratory at the Central Mining Institute in Katowice according to Polish standards.

Gasified bituminous coal (according to the UN + ECE classification) contains many moisture, ash and volatile parts. The total sulphur content is not high and amounts to $0.51 \%$ (as received).

\subsection{Stages of gasification process}

The coal gasification process was conducted in 2013 as part of the HUGE 2 project. The test lasted 6 days (142 h). Based on the results obtained, the process was divided into three stages (Table 2):

The gasification process was started by igniting a coal seam using a pyrotechnic charge. The ignition occurred with low oxygen flow rate $\left(2 \mathrm{Nm}^{3} / \mathrm{h}\right)$ supplied into the reactor inlet. After ignition of the coal, the oxygen flow rate was increased to $10 \mathrm{Nm}^{3} / \mathrm{h}$. The process initiation was considered complete when the concentration of oxygen in the process gas was below $1 \%$. Stage I of the coal gasification was started with an oxygen flow rate of $10 \mathrm{Nm}^{3} / \mathrm{h}$. After $45 \mathrm{~h}$ of the process, the oxygen flow rate was gradually increased to $15 \mathrm{Nm}^{3} / \mathrm{h}$. In the stage I, 


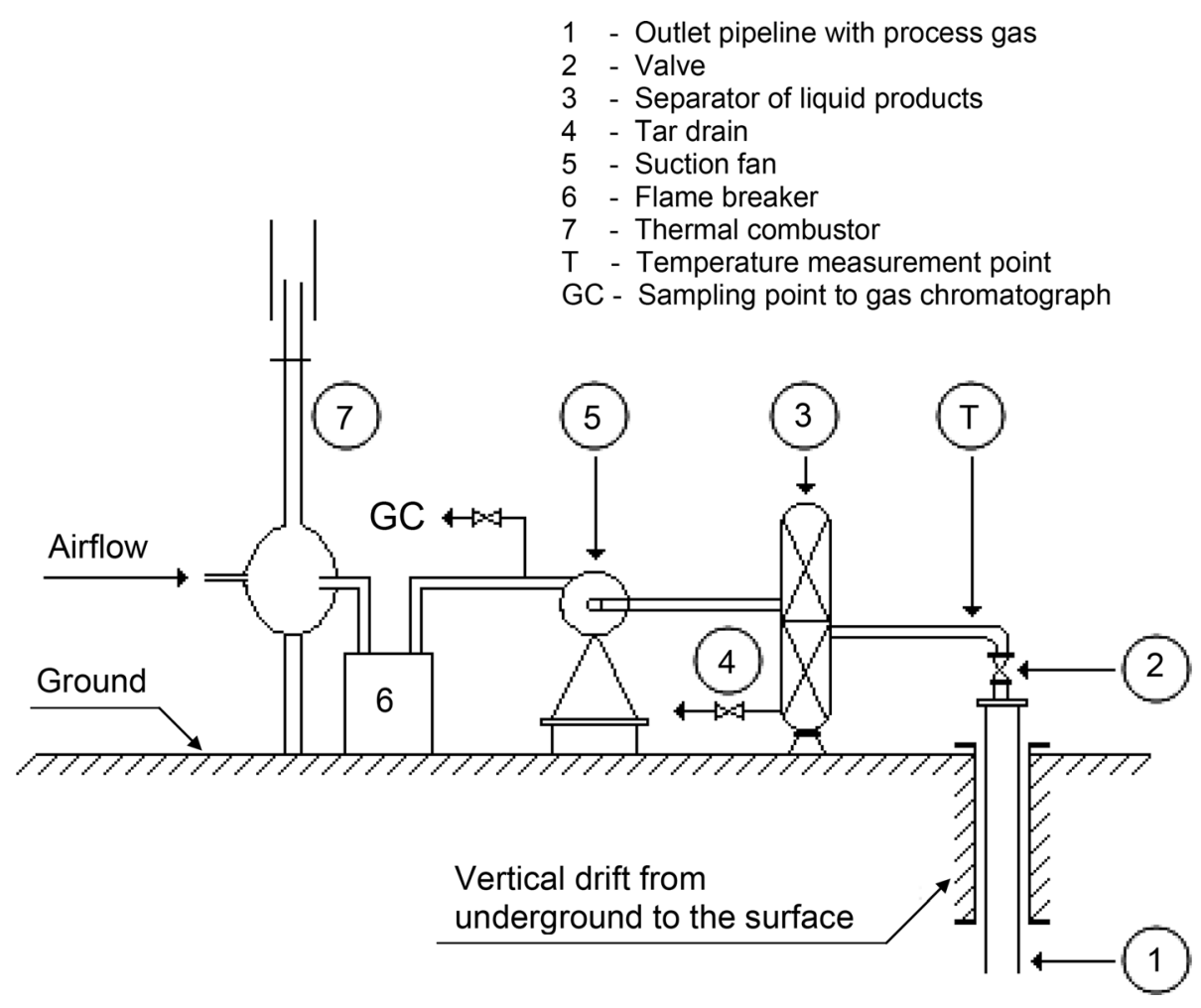

Fig. 2 Scheme of gaseous product collection system located on surface (Wiatowski et al. 2015)

Table 1 Proximate and ultimate analysis of raw coal from 'Barbara' mine

\begin{tabular}{lll}
\hline Item & Value & Standard \\
\hline As received & & PN-G-04511:1980 \\
Moisture $W^{\mathrm{r}}(\%)$ & 11.81 & PN-G-04560:1998 PN-ISO 1171:2002 \\
Ash $A^{\mathrm{r}}(\%)$ & 15.56 & PN-G-04584:2001 PN-ISO 334:1997 \\
Sulphur total $S^{\mathrm{r}}(\%)$ & 0.51 & PN-G-04513:1981 \\
Lower heating value $Q^{\mathrm{r}}(\mathrm{kJ} / \mathrm{kg})$ & 21,708 & PN-G-04511:1980 \\
Analytical & & PN-G-04560:1998 PN-ISO 1171:2002 \\
Moisture $W^{\mathrm{a}}(\%)$ & 6.39 & PN-G-04516:1998 PN ISO-562:2000 \\
Ash $A^{\mathrm{a}}(\%)$ & 16.52 & PN-G-04513:1981 \\
Volatile matter $V^{\mathrm{a}}(\%)$ & 29.84 & PN-G-04571:1998 \\
Lower heating value $Q^{\mathrm{a}}(\mathrm{kJ} / \mathrm{kg})$ & 23,192 & PN-G-04571:1998 \\
Carbon $\mathrm{C}^{\mathrm{a}}(\%)$ & 57.95 & PN-G-04571:1998 \\
Hydrogen $\mathrm{H}^{\mathrm{a}}(\%)$ & 3.70 & PN-G-04584:2001 PN-ISO 334:1997 \\
Nitrogen $\mathrm{N}^{\mathrm{a}}(\%)$ & 0.87 & PN-G-04584:2001 PN-ISO 334:1997 \\
Sulphur total $\mathrm{S}^{\mathrm{a}}(\%)$ & 0.54 & \\
Sulphur combustible $\mathrm{S}_{\mathrm{c}}^{\mathrm{a}}(\%)$ & 0.54 & \\
Oxygen $\mathrm{O}^{\mathrm{a}}(\%)$ & 14.03 &
\end{tabular}

stable parameters of the gasification process were observed. The process gas consisted (Fig. 3) of a high content of hydrogen and carbon monoxide and a low oxygen and nitrogen contents, which were not subjected to large fluctuation. The calorific value of the gas was high and amounted to $10-11 \mathrm{MJ} / \mathrm{Nm}^{3}$ (Fig. 4). 
Table 2 Stages of UCG test

\begin{tabular}{llll}
\hline $\begin{array}{l}\text { Stage } \\
\text { No. }\end{array}$ & Stage description & Time interval & \\
\hline 1 & Coal ignition and stable operation of coal gasification process & $0-101 \mathrm{~h}$ & Duration \\
2 & Unstable operation of process & $101-142 \mathrm{~h}$ & $101 \mathrm{~h}$ \\
3 & Extinguishing and cooling down of reactor & $142 \mathrm{~h}+4$ weeks & $41 \mathrm{~h}$ \\
\hline
\end{tabular}

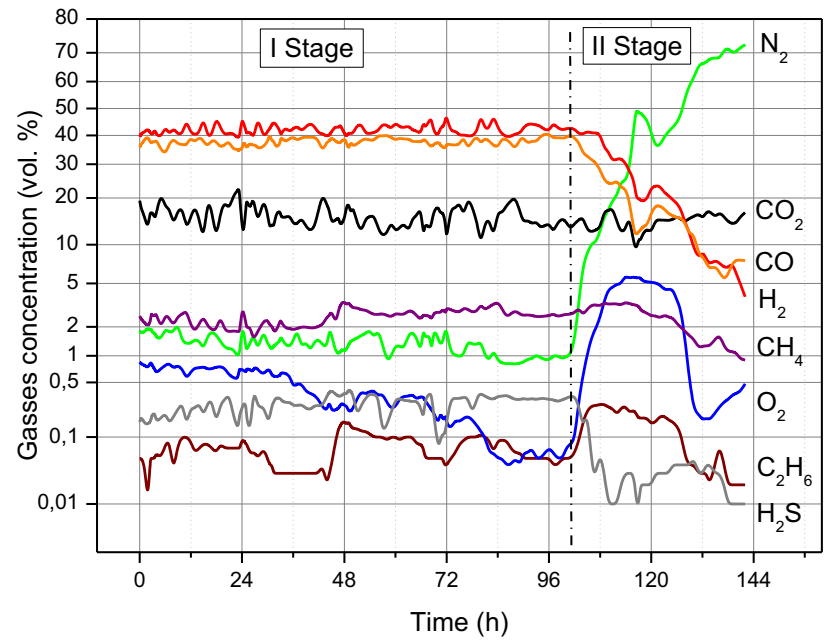

Fig. 3 Concentration of process gas components (Wiatowski et al. 2015)

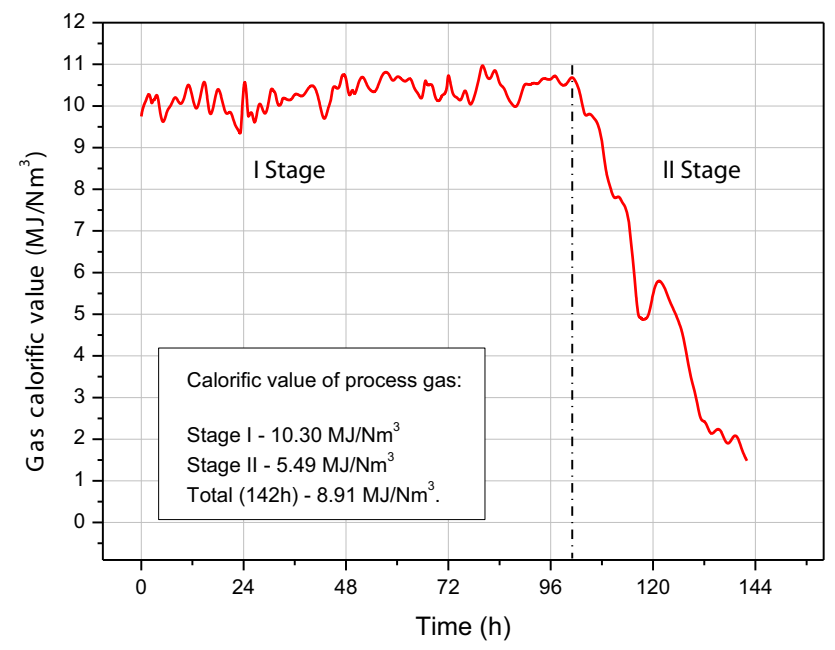

Fig. 4 Lower heating value of process gas (Wiatowski et al. 2015)

In the stage II of the process, starting from $101 \mathrm{~h}$, a rapid decrease in the concentrations of the combustible components of the process gas was observed with a simultaneous rapid increase in the nitrogen and oxygen contents. The calorific value (Fig. 4) of the gas produced began to decrease. Monitoring of air quality in the mine galleries showed the presence of reaction gases, especially carbon monoxide, carbon dioxide and hydrogen. The concentrations of these gases were initially low but increased to a high value by the end of gasification process. Their presence in the mine air indicated that the underground reactor was unsealed. Thus, due to safety reasons, this experiment was terminated by stopping the oxygen supply (after six full days from starting). Next, the reactor was cooled with a stream of nitrogen. The cooling rate was controlled by measuring the exhaust gas concentration as well as its temperature. The reactor cooling time was approximately 4 weeks. After that time, the conditions in the reactor returned to the initial conditions. Detailed data on the course of this gasification process and the construction of the reactor were described in earlier publications (Wiatowski et al. 2015; Wiatowski and Kapusta 2018).

\subsection{Temperature conditions in output pipeline}

Figure 5 shows the results of the process gas temperature measurement at a distance of $8 \mathrm{~m}$ from the reactor outlet, behind the water cooler (in the underground part) and on the surface at the tar sampling point.

As shown in Fig. 5, the temperature of the process gas at the reactor outlet was not high. In stage I, after ignition of the reactor, it was approximately $60{ }^{\circ} \mathrm{C}$ and gradually increased to the final value of $100{ }^{\circ} \mathrm{C}$. At the beginning of stage II, the gas temperature decreased and then increased

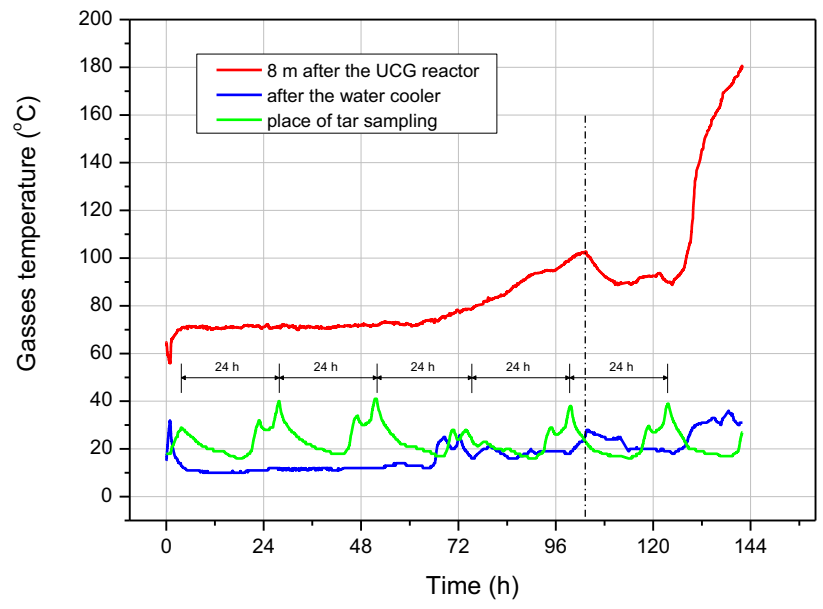

Fig. 5 Temperatures of process gas 
to a final value of $180{ }^{\circ} \mathrm{C}$. The gas temperature after passing through the water cooler did not exceed $30^{\circ} \mathrm{C}$ in stage I and $40{ }^{\circ} \mathrm{C}$ at the end of stage II. The gas temperature on the surface at the sampling site was subject to cyclical fluctuations in the range of $18-38{ }^{\circ} \mathrm{C}$. The observed temperature fluctuations occurred in a twenty four hours cycle and resulted from different temperature conditions outside the gas pipeline in the underground and aboveground sections. In the underground section, the gas pipeline was laid in the mine galleries with a constant air temperature of approximately $7{ }^{\circ} \mathrm{C}$. In the aboveground section of the installation, the temperature outside the pipeline depended on the current weather conditions and was higher during the day and lower at night.

\subsection{Testing of tar samples}

Tar samples were collected from the liquid product separator via the tar drain valve (Fig. 2) daily, with additional samples taken at the beginning (initial sample) and end of the test (final sample). The tar residence time in this place was several hours. The collected samples represent the part of the tar that, together with the process gas, has entered the surface and was separated from the gas in the separator of liquid products. The tar samples collected from the start of the gasification up to and including the 4th day relate to stage I. The sample taken on the 5th day of the test is a mixture of tars obtained partly in stage I and partly in stage II. The remaining samples, from the 6th day and the final sample, were collected in stage II after unsealing the reactor. The total amount of tar obtained during the whole test was not too high and was approximately $3 \mathrm{dm}^{3}$ (approx. $4.1 \mathrm{~kg}$ ), while the volume of a single sample was $0.2-0.6 \mathrm{dm}^{3}$. Considering that $9163 \mathrm{Nm}^{3}$ of process gas was obtained, the concentration of tar in the gas was 0.45 $\mathrm{g} / \mathrm{Nm}^{3}$. This is a low value for the underground gasification process. During the experiment, it was observed that as gasification progressed, the amount of tar collected from the separator systematically decreased, and at the end of the experiment, tar production practically stopped. After finishing the process and dismantling the pipeline through which the process gas flowed, it turned out that large amounts of tar mixed with dust were in the form of a layer approximately $1 \mathrm{~cm}$ thick deposited on the walls inside the pipeline. Taking this into account, the real tar yield may be higher. However, it is difficult to determine the amount of this tar because it was distributed inside the output pipeline very unevenly.

The tar samples taken from the liquid product separator were subjected to tests for analyses carried out as for typical coal tar. The samples were tested in their raw state. The analyses were carried out at the Institute of Chemical Processing of Coal in Zabrze. The methodology of their implementation was adopted from Polish standards for testing typical coal tar from the coke oven process. The standards of the individual tests were as follows:

(1) Water content by Karl-Fischer method (own laboratory procedure),

(2) Ash content, PN-77/C-97065 standard,

(3) Residue after coking (LK), PN-88/C97071 standard,

(4) Toluene insoluble components (TI), PN-82/C-97057 standard,

(5) Quinoline insoluble components (QI), PN-C97058:1999 standard,

(6) Elemental analysis C, H, N, S, Q/LG/15/A:2011 standard.

UCG tars are a black, dense liquid with a slightly noticeable characteristic smell that is much less intense than coal tar. They contain a very high amount of water and ash (mechanical impurities). Table 3 presents the results of a technical analysis of tars, while the results of an elementary analysis are presented in Table 4 . To make the results of the technical analysis independent of the water content, the results were calculated for the dry state, while the results of the elementary analysis were calculated for the dry and ash-free states (daf). The calculated results of the analyses make it easier to compare the properties of the tested tars because they characterize only the tar substances without taking into account the water and ash content, which is variable.

The tested samples of tars were distilled by separating them into individual fractions in accordance with the guidelines of the subject standard (PN-C-97055: 2001 standard) for coal tar. The maximum distillation temperature was $360{ }^{\circ} \mathrm{C}$. The yield of the obtained fractions is shown in Table 5, while the course of the tar distillation curves compared to the distillation curve of typical coal tar is shown in Fig. 6.

During the distillation of all tested samples, large amounts of fumes were observed, which were not condensed and were coming out of the cooler. This explains the high amount of distillation losses recorded in the mass balance of the distillation process.

The content of PAHs and heterocompounds in tars was determined by chromatography. The content of these compounds was determined according to the PN-C82056:2000 standard. The analysis was performed using a Thermo-Scientific gas chromatograph (model Trace). Quantitative analyses were performed using the internal standard method. The results of the analysis including compounds with content above $0.01 \%$ are shown in Table 6. The content of selected compounds (with the highest concentrations) in the tested UCG tar samples compared to the content of the same compounds in coal tar is shown in Fig. 7. 
Table 3 Technical analysis of tar samples (results were calculated for dry state)

\begin{tabular}{|c|c|c|c|c|c|c|c|c|c|}
\hline Item & Initial sample & 1 day & 2 day & 3 day & 4 day & 5 day & 6 day & Final sample & Coal tar \\
\hline Water content, W $(\%)$ & 35.7 & 20.3 & 16.8 & 2.9 & 5.8 & 5.5 & 3.4 & 1.5 & $1.5-5$ \\
\hline Ash content, A (\%) & 6.3 & 5.5 & 7.2 & 15.3 & 11.7 & 12.8 & 14.0 & 14.4 & to 0.1 \\
\hline Residue after coking, LK (\%) & 27.4 & 27.1 & 27.9 & 30.9 & 29.0 & 29.9 & 34.1 & 35.8 & $15-30$ \\
\hline Content of toluene insoluble matter, TI (\%) & 20.2 & 26.6 & 35.3 & 25.4 & 26.9 & 29.1 & 32.0 & 33.6 & $4-15$ \\
\hline Content of quinoline insoluble matter, QI (\%) & 9.1 & 16.8 & 21.2 & 27.7 & 21.5 & 23.1 & 32.9 & 37.2 & $1.5-5.5$ \\
\hline
\end{tabular}

Table 4 Elementary analysis of tested samples (daf)

\begin{tabular}{|c|c|c|c|c|c|c|c|c|c|}
\hline Item & Initial sample & 1 day & 2 day & 3 day & 4 day & 5 day & 6 day & Final sample & Coal tar \\
\hline Carbon content, $\mathrm{C}^{\mathrm{daf}}(\%)$ & 88.4 & 88.7 & 89.8 & 88.2 & 82.1 & 83.1 & 85.0 & 84.6 & $88-92$ \\
\hline Hydrogen content, $\mathrm{H}^{\mathrm{daf}}(\%)$ & 3.9 & 4.9 & 4.7 & 6.2 & 6.7 & 6.2 & 6.0 & 5.9 & $5-5.5$ \\
\hline Nitrogen content, $\mathrm{N}^{\mathrm{daf}}(\%)$ & 1.7 & 1.5 & 1.6 & 1.1 & 1.6 & 1.6 & 1.5 & 1.3 & $0.8-1.1$ \\
\hline Sulphur content, $S^{\text {daf }}(\%)$ & 1.5 & 1.9 & 2.3 & 2.2 & 2.3 & 2.1 & 2.1 & 2.2 & $0.3-0.6$ \\
\hline $\mathrm{H} / \mathrm{C}$ ratio & 0.53 & 0.66 & 0.62 & 0.84 & 0.97 & 0.90 & 0.85 & 0.84 & 0.72 \\
\hline
\end{tabular}

Table 5 Results of fractional distillation of tar samples

\begin{tabular}{|c|c|c|c|c|c|c|c|c|c|}
\hline Item & Initial sample & 1 day & 2 day & 3 day & 4 day & 5 day & 6 day & Final sample & Coal tar \\
\hline Start of boiling $\left({ }^{\circ} \mathrm{C}\right)$ & 100 & 99 & 101 & 103 & 98 & 105 & 108 & 102 & 98 \\
\hline \multicolumn{10}{|c|}{ Yield of fraction (vol\%) } \\
\hline to $170{ }^{\circ} \mathrm{C}$ & 30.8 & 16.2 & 11.2 & 9.7 & 7.7 & 6.3 & 4.3 & 2.4 & 3.0 \\
\hline $170-270{ }^{\circ} \mathrm{C}$ & 7.1 & 10.7 & 13.6 & 15.4 & 17.0 & 17.0 & 11.7 & 9.1 & 14.5 \\
\hline $270-330{ }^{\circ} \mathrm{C}$ & 12.3 & 9.5 & 13.7 & 13.8 & 13.7 & 14.2 & 14.6 & 15.1 & 9.5 \\
\hline $330-360{ }^{\circ} \mathrm{C}$ & 4.6 & 7.7 & 8.9 & 8.6 & 14.6 & 11.3 & 10.0 & 10.8 & 10.5 \\
\hline Residue & 33.1 & 43.2 & 52.6 & 45.6 & 41.3 & 46.5 & 53.5 & 55.3 & 61.5 \\
\hline Losses & 12.1 & 12.7 & 9.4 & 6.9 & 5.7 & 4.7 & 5.9 & 7.3 & 1.0 \\
\hline
\end{tabular}

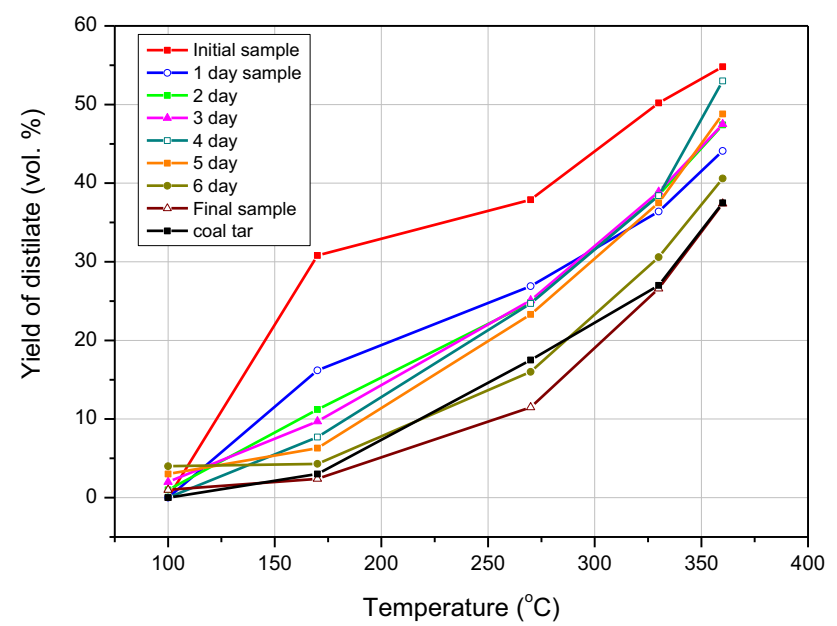

Fig. 6 Course of distillation of tar samples from UCG in comparison to course of distillation of coal tar
From the tested samples of tars, one was selected that showed the lowest tendency to thermal decomposition, assessed on the basis of the amount of distillation loss. This was the sample from the 5th day of the test, for which the distillation loss was $4.7 \%$ (Table 5). For this sample, chromatographic analyses of the composition of individual fractions obtained during distillation were performed. The content of the selected compounds with the highest concentrations in the obtained fractions is shown in Fig. 8 . After determining the concentration of a given compound and the yield of the corresponding distillate fraction, the content of individual components were calculated into the concentration (Sum) in the entire distilled sample. For comparison, the same graph (Fig. 8) also shows the content of the same compounds (Sample) determined directly from the same sample but without prior distillation. 
Table 6 Content of PAHs and heterocyclic hydrocarbons in tars

\begin{tabular}{|c|c|c|c|c|c|c|c|c|}
\hline PAH & $\begin{array}{l}\text { Initial sample } \\
\text { Content }(\%)\end{array}$ & 1 day & 2 day & 3 day & 4 day & 5 day & 6 day & Final sample \\
\hline Naphthalene & 1.60 & 2.76 & 1.04 & 1.51 & 0.59 & 0.97 & 0.77 & 0.97 \\
\hline 1-methylnaphthalene & 0.26 & 0.43 & 0.30 & 0.33 & 0.28 & 0.32 & 0.26 & 0.33 \\
\hline 2-methylnaphthalene & 0.36 & 0.65 & 0.36 & 0.51 & 0.41 & 0.46 & 0.38 & 0.48 \\
\hline Acenapthylene & 1.13 & 2.08 & 1.88 & 1.81 & 0.30 & 0.61 & 0.70 & 1.08 \\
\hline Acenaphthene & 0.05 & 0.10 & 0.05 & 0.14 & 0.10 & 0.09 & 0.08 & 0.18 \\
\hline Fluorene & 0.33 & 0.66 & 0.71 & 0.86 & 0.24 & 0.47 & 0.51 & 0.96 \\
\hline Phenanthrene & 0.75 & 1.55 & 1.83 & 1.97 & 0.57 & 0.92 & 1.10 & 2.09 \\
\hline Anthracene & 0.25 & 0.52 & 0.62 & 0.71 & 0.14 & 0.38 & 0.43 & 0.82 \\
\hline Fluoranthene & 0.37 & 0.83 & 0.94 & 0.84 & 0.15 & 0.32 & 0.41 & 0.80 \\
\hline Pyrene & 0.34 & 0.77 & 0.87 & 0.83 & 0.14 & 0.36 & 0.45 & 0.91 \\
\hline Benzo(a)anthracene & 0.19 & 0.50 & 0.52 & 0.41 & 0.12 & 0.15 & 0.17 & 0.31 \\
\hline Chryzene & 0.09 & 0.24 & 0.25 & 0.24 & 0.04 & 0.11 & 0.12 & 0.24 \\
\hline Benzo $(b+k)$ fluoranthene & 0.05 & 0.14 & 0.18 & 0.13 & 0.06 & 0.03 & 0.05 & 0.10 \\
\hline Benzo(e)pyrene & 0.04 & 0.09 & 0.10 & 0.08 & 0.02 & 0.03 & 0.03 & 0.07 \\
\hline Benzo(a)pyrene & 0.09 & 0.20 & 0.21 & 0.17 & 0.05 & 0.05 & 0.06 & 0.11 \\
\hline Perylene & 0.02 & 0.06 & 0.05 & 0.04 & 0.01 & $<0.01$ & 0.02 & 0.03 \\
\hline Dibenzo(a,h)anthracene + indeno(1,2,3-cd)pyrene & $<0.01$ & 0.02 & $<0.01$ & 0.02 & 0.01 & 0.01 & 0.01 & 0.01 \\
\hline $\operatorname{Benzo}(\mathrm{g}, \mathrm{h}, \mathrm{i})$ perylene & 0.05 & 0.13 & 0.13 & 0.11 & $<0.01$ & 0.04 & 0.04 & 0.08 \\
\hline Total PAHs & 5.97 & 11.73 & 10.04 & 10.71 & 3.23 & 5.32 & 5.59 & 9.57 \\
\hline \multicolumn{9}{|l|}{ Heterocyclic compounds } \\
\hline Chinoline & 0.06 & 0.13 & 0.17 & 0.17 & 0.16 & 0.09 & 0.09 & 0.16 \\
\hline Izochinoline & 0.04 & 0.06 & 0.09 & 0.08 & 0.07 & 0.07 & 0.50 & 0.09 \\
\hline Methylchinoline (sum) & 0.01 & 0.04 & 0.09 & 0.24 & 0.22 & 0.09 & 0.17 & 0.34 \\
\hline Dibenzofurane & 0.25 & 0.49 & 0.50 & 0.62 & 0.51 & 0.38 & 0.41 & 0.77 \\
\hline Benzotiophene & 0.08 & 0.11 & 0.05 & 0.06 & 0.05 & $<0.01$ & 0.03 & 0.03 \\
\hline Carbazole & 0.04 & 0.09 & 0.15 & $<0.01$ & 0.11 & $<0.01$ & 0.08 & 0.18 \\
\hline Total heterocyclic & 0.48 & 0.92 & 1.05 & 1.17 & 1.12 & 0.63 & 1.28 & 1.57 \\
\hline
\end{tabular}

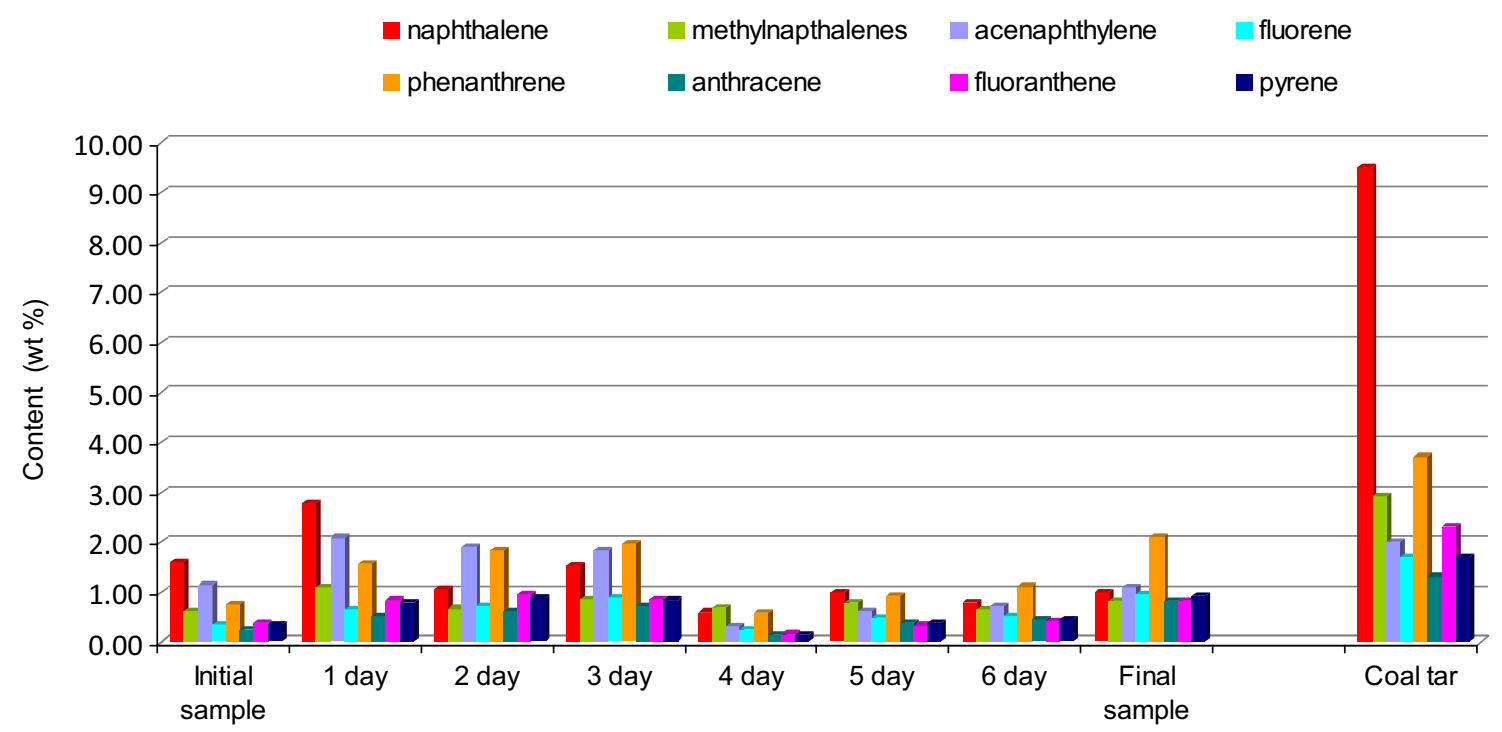

Fig. 7 Comparison of content of selected PAHs in tars from UCG and in typical coal tar 


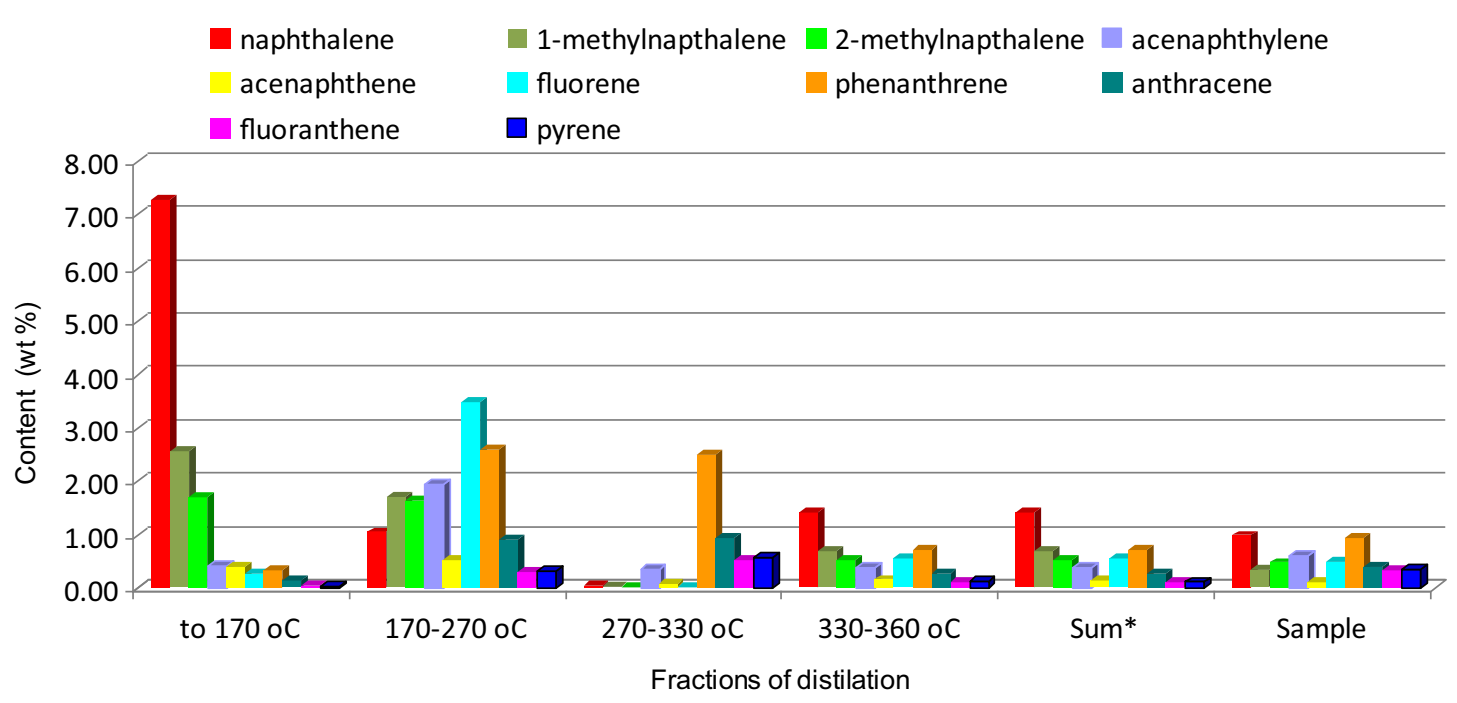

Fig. 8 Analysis of fraction composition obtained from tar sample distillation taken on 5th day of the gasification test *Total volume per sample, including fractional content of distillate

\section{Discussion of results}

\subsection{Properties of tar from UCG}

Samples of tars collected during the underground coal gasification test show a significant differentiation of properties; however, some regularities can be noticed. It is interesting that the properties of the tested tars change abruptly on the third day of the test. The observed changes are as follows:

(1) The water content at the beginning of the test is very high, from above $35 \%$ to approximately $3 \%$ on the 3 rd day. From the 4th day, the water content stabilizes and is maintained between $5.8 \%$ and $1.5 \%$ until the end of the test.

(2) The opposite trend is observed with regard to ash content. Starting with a relatively low content at the beginning of the test (at 6.3\%, calculated on a dry basis), we note an increase to $15.3 \%$ on the 3 rd day and stabilization at $14 \%$ at the end of the test.

(3) Relevant changes are also observed on the 3rd and 6 th days of the test in the value of coking residue. The LK on the 3rd day increases by approximately $3 \%$ compared to the previous day, while maintaining this value and slightly increasing on the last day of the test by the next $3 \%$.

(4) The content of substances insoluble in toluene TI, after an initial increase, decreases by approximately $10 \%$ on the third day despite an increase in ash content (which is entirely part of TI) and then gradually increases again, also with an increase in ash content. A similar but much less intense trend is observed for parts insoluble in quinoline.

(5) During the distillation of the tars, a clear decrease in distillation losses is observed for samples from the 3rd day of the gasification test. This indicates a change in the properties of the tars and a decrease in their tendency toward thermal decomposition.

The fractional composition of the tested tars (except for the sample at the beginning of the test) is very similar within certain limits. The tar sample taken at the beginning of the test (initial sample) shows a much lighter character than the other samples and is marked by an exceptionally high (over $30 \%$ ) content of fraction boiling up to $170{ }^{\circ} \mathrm{C}$. This value is $2-15$ times higher than for the other tar samples. For this sample, the distillation residue content is also significantly lower (33\%) and is over $40 \%$ for the other samples. The content of the remaining fractions for all samples shows no major differences, and the ranges of variation of the content of individual fractions are as follows:

(1) The content of fractions up to $170{ }^{\circ} \mathrm{C}$ systematically drops from $30.8 \%$ to $2.4 \%$,

(2) The content of fraction $170-270{ }^{\circ} \mathrm{C}$ takes values in the range $7.1 \%-17.0 \%$,

(3) The content of fraction $270-330{ }^{\circ} \mathrm{C}$ takes values in the range $9.5 \%-15.1 \%$,

(4) The content of fraction $330-360{ }^{\circ} \mathrm{C}$ takes values in the range $4.6 \%-14.6 \%$,

(5) The content of the distillation residue is approximately $50 \%$ except for the initial sample and the sample from the 4th day. 
All tested tar samples are characterized by very high distillation losses, which indicate their unstable properties. High distillation losses from approximately 5\% to almost $13 \%$ are due to the tendency toward thermal decomposition of tar during heating. A visible sign of the thermal decomposition of UCG tars is the large amount of white fumes produced during their distillation, which are emitted from the cooler. The presence of these fumes results from the decomposition of unstable components contained in tars during heating. These compounds have not been identified, but it can be assumed that they are macromolecular compounds of the nature of oligomers and resins, which at elevated temperatures depolymerize to light products, including gaseous ones. The elemental composition of the tested samples is stable, with a noticeable tendency to change after $2-3$ days of the test. The carbon content in the first three days of gasification is $88 \%-89 \%$; from the 4 th day, it decreases by approximately $6 \%$ and then slightly increases until the end of the experiment. The hydrogen content of the initial sample is the lowest and is 3.9\%; from the 3rd day, it increases by $1.5 \%$ and maintains a constant level. It can be seen that the $\mathrm{H} / \mathrm{C}$ ratio increases up to the 4th day and then decreases until the end of the experiment. This indicates changes in the degree of hydrogenation of the tar samples, initially increasing and later decreasing. The nitrogen and sulphur content takes values between 1.1 and $1.7 \%$ for nitrogen and $1.5 \%-2.3 \%$ for sulphur. The relatively high sulphur content in the tars results from the sulphur content in raw coal subjected to gasification $(0.51 \%)$ and a relatively small amount of tar obtained in the gasification process, which gives a high concentration of sulphur compounds condensed in the process gas treatment system.

A chromatographic analysis of the tested samples did not show any significant differences in the content of the identified compounds. There is no component whose content is by far the highest for all samples. The content of naphthalene is highest only in the first two tar samples; in the samples taken from the second day, the predominant components are phenanthrene, acenaphthylene and methylnaphthalenes. A surprise may be the lack of identified light aromatic compounds from the BTEX group in the tars. The lack of these compounds is mainly due to their volatility, which is especially high for benzene. These compounds, despite the low-temperature conditions in the pipeline and at the tar sampling point, were in the gas phase (some in the form of aerosols). In this form, in the process gas stream, they moved to the thermal combustor, where they were burned. This is evidenced by the results of similar tests (Wiatowski et al. 2017; Wiatowski and Kapusta 2020) in which the composition of tars collected directly from the process gas in the output pipeline before entering the separation system and the composition of the same tars after their separation were tested. There were many BTEX compounds in the tars taken directly from the process gas, while in the tars after separation, these compounds were not found.

The total content of identified compounds, mainly PAHs, is relatively low and does not exceed $13 \%$. In combination with high content of TI and QI with high distillation losses, this is an additional confirmation of the high content of macromolecular compounds susceptible to thermal decomposition. The thesis of susceptibility to thermal decomposition is also confirmed by the results of an analysis of the composition of fractions obtained from the distillation of a selected tar sample from the 5th day of the test. Thermal decomposition takes place during heating of the distilled tar in a distillation flask where the temperature is slightly higher than the boiling point of the distillate received. For this sample, the compliance of the content of the determined compounds in the initial tar sample (without distillation) and in the fractions obtained from distillation occurs only for 2-methylnaphthalene, fluorene and acenaphthene. For most of the determined compounds, a decrease in their content in the fractions from the distillation in relation to the initial tar is visible. This especially concerns acenaphthene, phenanthrene, anthracene, fluoranthene, pyrene, benzo(a)anthracene and chrysene. This is due to the thermal decomposition of these compounds during heating to compounds of different compositions and lower molecular weights. The observed effect of this phenomenon is the resulting fumes that come out of the cooler during distillation.

An increase in the content of compounds in the distilled fractions in relation to nondistilled tar was noted for compounds forming stable aromatic structures such as naphthalene and. 1-methylnaphthalene, which may be formed in the decomposition reactions of heavier compounds. It should be expected that for the remaining samples of tars for which the distillation losses are higher (even more than twice), the thermal decomposition reactions are much more intense. Distillation losses are quick, simple and the most reliable indicator of the intensity of the thermal decomposition reaction of the tar sample during heating.

During the experiment, it was observed that the amount of tar produced gradually decreased and practically stopped at the end of the process. This is due to the decrease in the intensity of coal pyrolysis processes with the progress of gasification. This phenomenon was also observed in other similar underground coal gasification trials (Wiatowski et al. 2012; Wiatowski and Kapusta 2020). 


\subsection{Comparison of properties of UCG tar with coal $\operatorname{tar}$}

Coal tar from the coke oven battery process is the only product obtained from thermal coal processing on an industrial scale in Poland. It is a mass commercial product that is further processed by distillation. Despite the fact that UCG tar and coke oven tar are made of the same type of raw material (hard coal), the properties of these tars differ significantly from each other. Particularly noteworthy is the very high ash content in the tars after underground gasification, amounting to approximately $6 \%-15 \%$, with the values for coke oven tar at a level of tenths or even hundredths of a percent. Such a high ash content results from lifting most of the mineral substances (and coal dust) from the gasified coal in the process gas and accumulating them in the tar. It is possible to reduce the ash content several times in different physical processes in a properly conducted tar preparation process (standing and centrifuging), but it is very difficult to obtain the ash content at a level analogous to that of coke oven tar without extraordinary effort. The consequences of the high ash content include significantly higher values than for coke oven tar; these are related to the tar group composition.

The residue after coking LK is approximately twice that of coal tar, and the content of insoluble parts in both toluene and quinoline is many times higher. It should also be noted that the properties of substances insoluble in toluene and quinoline occurring in UCG tars are different from those of coke oven tar. Tars from UCG are to a large extent mineral and carbon particles and oligomeric macromolecular compounds susceptible to thermal decomposition (depolymerization). However, coal tar is mainly composed of high-molecular-weight polyaromatic compounds with a small amount of carbon and coke particles.

The high water content in the tar samples collected at the beginning of the test stabilizes from the third day at a level similar to that of coal tar. The elemental composition of UCG tar is similar to the elemental composition of coal tar with the exception of sulphur content, the concentration of which in coal gasification tar is 3-4 times higher than in coal tar. This is most likely due to the much smaller amount of tar produced in this UCG process compared to coking, with a similar amount of sulphur compounds being transferred from coal to tar. The carbon content is at a similar level, and the hydrogen content is slightly higher in the tested tars, which can be explained by the lower content of aromatic hydrocarbons with a higher content of aliphates and naphthenes.

Additionally, the nitrogen content of the UCG tars is slightly higher. The distillation course for the samples from UCG was essentially analogous to that of coal tar (Fig. 6), with the exception of the first-day sample deviating from the other samples in terms of a higher lightest fraction content and significantly higher distillation losses. The remaining samples, compared to coke-oven tar, usually showed a higher content of each fraction up to $360^{\circ} \mathrm{C}$, with greater differences noted only at the beginning of the test. The residue after distillation for the tested gasification tars, lower than for coal tar, should actually be considered even lower after taking into account the ash content, which is incomparably higher than for coal tar and is inert in the distillation process.

Losses during distillation, minimal for coal tar (less than $1 \%$ ), are significantly higher for the samples tested and range from $5 \%$ to $13 \%$ due to differences in the stability of these products. The first symptoms of the thermal decomposition process (appearance of fumes from the cooler) for the tested samples were observed at the collection of the first fraction (up to $170{ }^{\circ} \mathrm{C}$ ), which indicates the beginning of these processes at a temperature of $150{ }^{\circ} \mathrm{C}$. For coal tar, thermal decomposition starts at a temperature of approximately $400{ }^{\circ} \mathrm{C}$, in which the beginning of the coking process is observed. Chromatographic analysis of the composition of the tar samples showed that there is no compound whose content clearly dominates, such as naphthalene in coal tar. The contents of compounds above $1 \%$ are recorded only for naphthalene, phenantrene and acenaphthylene, with their highest concentration value not exceeding $3 \%$. Tars from the analysed UCG process, unlike coal tar, which is a polyaseotropic and polyeutectic mixture of aromatic compounds, do not show a distinct aromatic character.

\section{Summary}

Tars obtained in the process of underground coal gasification constitute a small share of the gasification reaction products. However, the mass character of the coal gasification process in the case of its industrial and commercial implementations obliges an assessment of the properties of the resulting tars, which is the first step in determining the direction of possible product utilization. During the six-day underground gasification test, eight samples were collected that show significant differences in basic properties. This proves that the process parameters changed during the test. It is noticeable that the quality parameters of tars stabilized since the 3rd day of the test. This gives the prospect of obtaining a product with stable properties, for which the direction of utilization should be found.

The results obtained indicate that for the only method of disposal from tar from underground coal gasification not to be landfilled as hazardous waste, it is necessary to undergo a purification process. To consider any functional use of 
these tars, it is necessary to remove excess ash and other inert substances by means of standing or other physical methods. This will allow us to take into account the disposal of tar as a component of liquid fuels and heavy fuel oils after issuing and energy tests. It is also possible to use these tars as fuel for cement plants or in waste incineration plants as well as a component of bonding agents for the electrode industry. The high ash content excludes the addition of coke-oven tar processed by distillation to the stream without costly upgrading operations (centrifugation and filtration) due to very high quality requirements for coal pitch produced from coal tar. However, any management of tars from the UCG process, due to their properties, must be preceded by detailed research.

\section{Conclusions}

Based on the research carried out, the following conclusions can be drawn:

(1) The conditions of the gasification process have a significant influence not only on the quality of the gas obtained but also on the properties of liquid tar products, which are a by-product of the UCG process. After obtaining the stabilized process parameters of UCG (until the reactor is unsealed), the fluctuation of the properties of the produced tars decreases significantly and occurs only to a limited extent.

(2) In the conducted underground gasification test, only the properties of the first initial tar sample are different from the others due to the intensive release of volatile components from coal at this stage of the process. After the stabilization of the process parameters, which took place on the 3rd day of the test, a jumping change in the properties of the analysed tars was observed. The water content is significantly reduced while the ash content is increased. For the other parameters of the technical analysis, significant changes were also observed on the 3rd day of the test.

(3) The tested tars show a strong tendency to thermal decomposition, which was found on the basis of the course of distillation during which intensive fumes and very high distillation losses in the mass balance of the distillation were noticed. This thesis is confirmed by the composition of the tested tar samples: low content of stable aromatic compounds and high content of macromolecular compounds of oligomeric character (TI, QI), which were susceptible to depolymerization.
(4) The tars from the UCG process are different from coal tar both in terms of technical analysis properties and chemical composition. The samples tested differ from coal tar by the content of impurities (ash, TI and QI), susceptibility to thermal decomposition reactions and low content of aromatic hydrocarbons.

(5) The tested tars are similar to coal tar in terms of elemental composition and the course of distillation (except for the initial sample), excluding distillation losses.

(6) Any useable treatment of tar from UCG must be preceded by appropriate preparation to remove excess ash by physical methods.

(7) The absence of BTEX compounds in the tested tars was caused by their high volatility, as a result of which they did not condense in the gas cleaning installation and together with process gas were burned in the thermal combustor. In the case of the UCG process on an industrial scale, the gas cleaning system should be equipped with an installation for efficient recovery of BTEX compounds.

Author contributions MW: Conceptualization, Methodology, Experiments, Analysis, Writing — review \& editing; RM: Methodology, Analysis, Writing-review \& editing; KK: Conceptualization, Methodology, Visualization, Project administration; MC: Methodology, Analysis, Writing-review \& editing. All authors have read and agreed to the published version of the manuscript.

Funding This work was a part of the HUGE 2 project and was jointly supported by the Research Fund for Coal and Steel, under contract RFCR-CT-2011-00002 and by the Polish Ministry of Science and Higher Education.

\section{Declarations}

Conflict of interest The authors declare that they have no known competing financial interests or personal relationships that could have appeared to influence the work reported in this paper.

Ethical approval The experiments comply with the current laws of Poland.

Open Access This article is licensed under a Creative Commons Attribution 4.0 International License, which permits use, sharing, adaptation, distribution and reproduction in any medium or format, as long as you give appropriate credit to the original author(s) and the source, provide a link to the Creative Commons licence, and indicate if changes were made. The images or other third party material in this article are included in the article's Creative Commons licence, unless indicated otherwise in a credit line to the material. If material is not included in the article's Creative Commons licence and your intended use is not permitted by statutory regulation or exceeds the permitted use, you will need to obtain permission directly from the copyright holder. To view a copy of this licence, visit http://creativecommons. org/licenses/by/4.0/. 


\section{References}

Akbarzadeh H, Chalaturnyk RJ (2014) Structural changes in coal at elevated temperature pertinent to underground coal gasification: a review. Int J Coal Geol 131(1):26-146

Barbour FA, Campbell SL, Covell JR (1988) Analysis of coal tars collected from Rocky Mountain 1 ELW and CRIP Module. Western Research Institute Laramie, Wyoming, Work Performed Under Cooperative Agreement DE-FC21-86 MC11076 forU.S

Barbour FA, Cummings RE (1986) Comparison of coal tars generated by pyrolysis of Hanna coal and UCG Hanna IVB coal tars. Laramie, Wyoming: Western Research Institute U.S

Bhutto AW, Bazmi AA, Zahedi G (2013) Underground coal gasification: from fundamentals to applications. Prog Energy Combust Sci 39:189-214

Burton E, Friedman J, Upadhye R (2006) Best practices in underground coal gasification. U.S. Lawrence Livermore National Laboratory LLNL-TR-225331

Cena RJ, Thorness CB (1981) Underground Coal gasification Data Base. Lawrence Livermore National Laboratory, University of California, Livermore, California-94550

Chiranjeeva RS, Vinodbabu Ch, Vykunta RM (2015) Techniques of tar removal from producer gas-a review. Int J Innov Res Sci, Eng Technol 4(2):258-266

Cough GR. Underground coal gasification (2009) CCC/151, IEA, Clean Coal Centre, London

Department of Energy \& Climate change (2009) Development of Underground Coal Gasification for Power Generation. UKChina Technology Transfer. Contract Number: W/44/00658/00/ 00, URN Number: 09D/679. Canfield University: 1-97

Elliott MA (1981) Chemistry of coal utilization. 2nd Suppt, United States

Greg P (2018) Underground coal gasification Part I: field demonstrations and process performance. Prog Energy Combust Sci 67:158-187

Gregg DW, Edgar TF (1978) Underground coal gasification. AIChE J $24: 753-781$

Karabon B (2002) Smoła węglowa i benzol koksowniczy jako surowce przemysłu chemicznego. Oficyna Wydawnicza Politechniki Wrocławskiej, Wrocław (in Polish)

Klimenko A (2009) Early ideas underground coal gasification and their evolution. Energies 2:456-476
Kreinin EV, Fedorov NA, Zvyagintsev KN, Pyankova TM (1982) Underground gasification of coal seams. Nedra, Moscow

Liu S, Li J, Mei M, Dong D (2007) Groundwater pollution from underground coal gasification. J China Univ Min Technol 17:0467-0472

Liu E, Wang Z, Li S, Song W, Zhang H (2020) Staged condensation of coal tar from the pyrolysis of coal in a screw pyrolyzer. Chem Eng Technol 43(7):1442-1450

Olness D (1982) The Angrenskaya underground coal gasification station. Lawrence Livermore National Laboratory, University of California, Livermore, California - 94550

Pavlovich LB, Strakhov VM (2013) Producing hydrocarbons by the underground gasification of coal. Coke Chem 56:349-355

Philips NP, Muela CA (1977) In-situ coal gasification: status of technology and environmental impact. Radian Corporation P.O. Box 9948, Austin, Texas 78766. Prepared for U.S. Environmental Protection Agency, Office of research and Development, Washington D.C

Review of the feasibility of underground coal gasification in the UK (2004) by Cleaner Fossil Fuels Programme. Department of Trade \& Industry, Great Britain

Vreugdenhil, BJ and Zwart RWR (2009) Tar Formation in pyrolysis and gasification. Energy Research Center of the Netherlands, ECN-E-08-087, Petten

Wiatowski M, Kapusta K (2018) Study of tars properties obtained from underground coal gasification trials. Fuel 228:206-214

Wiatowski M, Kapusta K (2020) Evolution of tar compounds in raw gas from a pilot-scale underground coal gasification (UCG) trial at Wieczorek mine in Poland. Fuel 276:1-9

Wiatowski M, Kapusta K, Stańczyk K (2017) Analysis and characteristics of tars collected during a pilot-scale underground coal gasification (UCG) trial. Fuel 208:595-601

Wiatowski M, Kapusta K, Świądrowski J, Cybulski K, LudwikPardała M, Grabowski J, Stańczyk K (2015) Technological aspects of underground coal gasification in the experimental " Barbara"' Mine. Fuel 159:454-462

Wiatowski M, Stańczyk K, Świądrowski J, Kapusta K, Cybulski K, Krause E, Grabowski J, Rogut J, Howaniec N, Smoliński A (2012) Semi-technical underground coal gasification (UCG) using the shaft method in experimental mine "Barbara." Fuel 99:170-179 